\title{
LOS ESTADIOS DE DESARROLLO ORGANIZACIONAL
}

\author{
Joaquín Gairín Sallán \\ Universidad Autónoma de Barcelona
}

\begin{abstract}
RESUMEN. Diferentes circunstancias socio-culturales, la historia propia y los retos planteados como organización explican la diversidad existente entre los centros educativos. Podemos encontrar dentro de ellos, no obstante, elementos comunes que permiten elaborar una teoría sobre diferentes estadios de desarrollo organizacional. Más aún, establecer relaciones entre el estadio organizativo, las estructuras y estrategias de funcionamiento y los modelos educativos de enseñanza y de formación permanente que implícita o explícitamente se aplican. El establecimiento de modelos de análisis nos permite estudiar los niveles de coherencia que tiene la práctica educativa, a la vez que descubrir posibles disfunciones. Una institución de calidad ha de ser, como mínimo, coherente y tratar de disminuir las disfunciones existentes, si entendemos la calidad como compromiso con un desarrollo positivo que trata de mejorar las posiciones de partida.

ABSTRACT.A Different socio-cultural circumstances, history itself and the posed challenges as an organization explain the existing diversity in the schools. However, among these, one can find common elements which allow one to work out a theory about different stages of organizational development. Moreover, it allows one to establish relationships in the organisational stage, structures and strategies of working. Besides, educative models for teaching and for permanent education, which are applied implicity or explicitly. Establishing models of analysis allows one to study the levels of coherence of teaching as well as to discover possible problems. An institution of quality must be, at least, coherent. It must also try to decrease the existing problems if one understands that quality is commitment to positive development which will enhance starting positions.
\end{abstract}

\section{A modo de introducción}

La existencia de procesos de descentralización administrativa y política ha impulsado el planteamiento de la descentralización educativa y, con ella, la autonomía institucional, como realidad reciente y progresiva que se hace patente en nuestro sistema educativo. Acercar la educación a los contextos próximos y a los ciudadanos, por razones sociales, culturales, políticas, económicas o propiamente educativas ya analizadas (Gairín, 1996a),es una respuesta plausible vinculada a las exigencias educativas que conlleva un mayor dinamismo de la realidad socio-económica y una mayor participación ciudadana en el desarrollo de sus derechos básicos. 
La autonomía permite aproximar los centros educativos a su entorno inmediato, facilitando una adaptación de la oferta educativa a las demandas específicas de los usuarios, posibilitando la atención a la diversidad de los estudiantes e impulsando una mayor implicación y responsabilidad en los procesos y resultados de todos los implicados en el hecho educativo.

Genera, por otra parte, respuestas específicas y diferenciadas a problemáticas de base común. El desarrollo de la autonomía consagra, de hecho, la existencia de distintas propuestas y enriquece el panorama organizativo. Pueden así distinguirse distintas soluciones a problemas comunes y problemáticas diferentes que son abordadas desde una misma perspectiva.

Ordenar y clasificar las diferentes situaciones organizativas que se dan puede tener sentido, siempre y cuando se considere desde la perspectiva descriptiva y no desde la normativa. No se trata tanto de decir cómo deben ser los centros educativos como de conocer, a través del análisis de las diferentes propuestas, vías, que podrían o no adoptarse, para el desarrollo organizacional.

Desde esta perspectiva hablamos de estadios, en referencia al conjunto de circunstancias que concurren en una determinada realidad. $Y$ no consideramos la terminología de nivel, en la medida en que no admitimos que puedan existir grados de desarrollo organizacional; más bien pensamos que los centros educativos como organizaciones tienen un nivel de desarrollo determinado, consecuencia de su historia, inquietudes y compromisos, no comparable con el de otras realidades. Lo deseable, en todo caso, es que cada institución mejore respecto a la situación en la que se encontraba, esto es, que avance como organización de acuerdo a su proyecto pedagógico y a su compromiso socio-cultural.

Bajo estos supuestos, el artículo presenta varios estadios organizativos relacionándolos con otros aspectos de la intervención educativa, como puedan ser el modelo de educación, de enseñanza, estructuras organizativas o modelos de formación del profesorado. Las relaciones son sútiles y no siempre evidentes ni evidenciables. Por ello, cabe considerar la aportación como una primera aproximación para la reflexión, el análisis y, por supuesto, la profundización. De antemano, presentamos algunas evidencias y convicciones que se relacionan con lo que tratamos.

Actúan como evidencias, las siguientes:

- Los centros educativos como organizaciones tienen comportamientos similares y diferentes. Permite ello su clasificación, más que su ordenación por niveles, que no excluye el reconocimiento de su especificidad.

- La clasificación guía el análisis y orienta la intervención, sin dejar de reconocer la necesidad de contextualizar la intervención y las limitaciones que acompañan a cualquier acotación de la realidad.

- Un exceso de contextualización, además de limitar el desarrollo de las organizaciones a las propias posibilidades del entorno, elimina la idea de que pueda existir un conocimiento válido e intercambiable a otras realidades.

Podemos considerar como convicciones:

- Las organizaciones se pueden describir.

- El uso de determinados descriptores nos permite pensar en diferentes situaciones diferenciales. 
- Las situaciones diferenciales pueden categorizarse en un "continuum" donde es posible determinar posiciones características.

- La delimitación de niveles de desarrollo organizacional puede ayudar tanto a comprender el funcionamiento de las organizaciones como a su mejora.

- La posición en un determinado estadio no presupone un buen funcionamiento organizativo si no ha habido mejoras respecto a situaciones anteriores.

- Situarse en una determinada posición es una circunstancia puntual sujeta a los cambios que imponga el dinamismo de la realidad pasada y presente.

Desde la perspectiva señalada, podemos considerar varios estadios organizativos con sus características propias y relacionarlos con los distintos modelos de educación y enseñanza imperantes, siguiendo las aportaciones ya realizadas en Gairín, 1997b.

El establecimiento de modelos de análisis nos permite estudiar los niveles de coherencia que tiene la práctica educativa, a la vez que descubrir posibles disfunciones. Una institución de calidad ha de ser, como mínimo, coherente y tratar de disminuir las disfunciones existentes, si entendemos la calidad como compromiso con un desarollo positivo que trata de mejorar las posiciones de partida.

La simplificación de la realidad que se realiza a través de los modelos que se presentan trata, más que de acotarla, de orientar los procesos de explicación y, en todo caso, de facilitar los procesos de intervención. Se busca así proporcionar elementos que orientan la reflexión, el análisis y el cambio de la realidad a través de la búsqueda de una mayor coherencia en las actuaciones prácticas que se realizan.

\section{Los estadios de desarrollo organizacional}

La situación de las organizaciones suele ser diferente aunque nos movamos en un mismo contexto socio-cultural. La especial manera como se relacionan sus componentes, la acción diferenciada de la dirección, la forma como se aplica el proceso organizativo, la propia historia institucional y sus inquietudes en relación a la mejora, configuran diferencias y dan una personalidad única y particular a cada institución.

\subsection{Niveles de desarrollo}

Desde una perspectiva analítica, podríamos considerar que las organizaciones presentan diferentes estadios de desarrollo de acuerdo en la síntesis recogida en el gráfico 1.

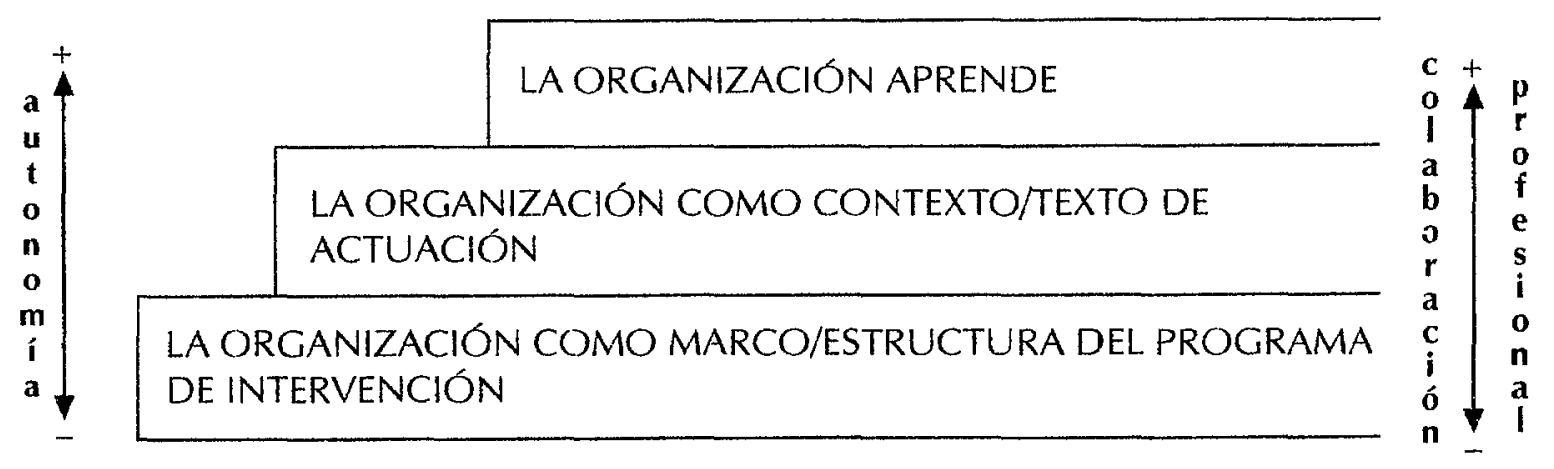

Gráfico 1: Estadios relativos al papel de la organización. 
Tradicionalmente, los sistemas educativos, sociales o culturales han determinado el contenido y condiciones del proceso que se había de desarrollar en las instituciones especializadas. La política educativa, social o económica definía y la Administración correspondiente concretaba y transmitía a las instituciones decisiones relativas al qué, cómo y cuándo formar y evaluar. Las instituciones de formación se consideraban así dependientes de las decisiones externas. A este nivel, la mayor preocupación se centra en la transmisión de los conocimientos establecidos, siendo importante para los profesores la dimensión didáctica del Programa de intervención y, más concretamente, los aspectos metodológicos.

Bajo una situación de autonomía, se plantea el reto de la ordenación curricular, que incluye decisiones de aula y de institución. Paralelamente a una preocupación sobre los procesos de enseñanza-aprendizaje en el aula, que conlleva plantearse los diferentes elementos del proceso didáctico y no sólo los aspectos metodológicos, surge la necesidad de definir y desarrollar los planteamientos institucionales. La actuación colectiva se hace así imprescindible y surge la preocupación por los procesos organizativos. De hecho, si en la situación anterior podemos hablar de "procesos de gestión", ahora tratamos de "procesos organizativos".

El primer estadio se podría identificar con la situación que asigna un papel secundario a la organización. Lo importante es el Programa de intervención y la organización resulta ser el continente, que, según como se adecue, podrá facilitar o no el desarrollo del Programa. El papel asignado a la organización resulta ser así subsidiario y fácilmente substituible; de hecho, el Programa podría darse en otro marco de actuación, si así se decidiera, y la formación pretendida no tendría necesariamente porque resentirse.

Esta concepción y el papel asignado a la organización ha estado y está presente en muchas actuaciones. Podríamos decir que, a menudo, el proceso organizativo actúa como soporte a un programa, proporcionando para su desarrollo espacios, tiempos, normativa, recursos humanos u otros requerimientos; esto es, adecuando los recursos a las tareas asignadas con la pretensión de alcanzar los estándares establecidos. Actúa así como continente de la acción formativa y no siempre lo hace desde una perspectiva positiva. Sucede esto, por ejemplo, cuando no se preserva el desarrollo del currículum de ruidos, interrupciones, falta de recursos, mala formación del profesorado/ técnicos, etc. a través de la acción organizativa.

El segundo estadio implica una posición activa por parte de las organizaciones. Existen explicitados planteamientos institucionales, llámense Proyecto Institucional, Proyecto Educativo, Programa de intervención u otros, que definen las metas de la organización que se tratan de conseguir. Este compromiso exige una toma de conciencia colectiva que obliga a reflejar compromisos más allá del espacio aula o de la acción individual del profesor.

Si una institución asume como compromiso estar abierta a todos los ciudadanos e intenta hacerlo efectivo, deberá reflejarlo en sus planteamientos institucionales y cumplirlo a través de prácticas educativas efectivas que concretan tanto las políticas generales como las que se aplican día a día. Se imponen actuaciones que van más allá del trabajo del aula y que implican la modificación de las estructuras de funcionamiento, el cambio de actitudes y prácticas del personal, el trabajo colectivo o el desarrollo de programas paralelos y complementarios a aquél. En estas condiciones, la ordenación 
que se realiza del contexto organizativo, de acuerdo a las exigencias internas y externas, ayuda a conformar la formación que a nivel de aula se pretende impulsar.

El desarrollo de actividades dirigidas a sensibilizar a la comunidad de la importancia de la diversidad, la organización efectiva de la tutoría individualizada, la potenciación de actividades dentro o fuera de la organización que fomenten la convivencia de los usuarios independientemente de sus características, la organización flexible o la formación de grupos cooperativos de aprendizaje $\mathrm{u}$ otras propuestas contribuyen a configurar un espacio educativo conformador de actitudes y transmisor de unos determinados valores.

Los pilares en los que se apoya una organización que educa son para Santos (1995):

a) La racionalidad, en referencia a la disposición lógica de los elementos y a la dinámica organizativa de acuerdo a los logros que se pretende conseguir.

La racionalidad exige revisar los objetivos, estructura, sistema de relaciones, dirección, etc., para averiguar en estos elementos y en su interrelación el nivel de coherencia existente. Supone estar también atentos a las relaciones existentes entre la organización formal e informal. La racionalidad ha de someterse también al principio de justicia, lo que exige plantearse, paralelamente a la coherencia, la ética de las prácticas que se desarrollan y que muchas veces se olvida al convertir la organización más en un fin que en un medio.

b) La flexibilidad, entendida como la capacidad de adecuarse a las exigencias de la práctica y, además, a los cambios que se producen en la sociedad.

La flexibilidad frente a la rigidez y no cambio produce ineficacia cuando nos movemos en contextos dinámicos, dada la inadecuación que se produce entre la organización y las exigencias cambiantes del entorno. También se potencia la ineficacia cuando procesos uniformadores impiden la adecuación de las instituciones educativas al contexto en el que tienen que actuar.

c) La permeabilidad o apertura al entorno próximo y mediato. Exige establecer y desarrollar mecanismos bidireccionales por los que la institución rompe su clausura proyectándose en el entorno y abriéndose a sus influencias.

La proyección externa exige el que las instituciones formativas proporcionen conocimientos sobre la realidad social, a la vez que la preparación necesaria para su inserción en el mercado laboral. Y todo ello desde una plataforma ética y crítica que permita comprender las contradicciones que se dan entre la realidad deseable y la realidad existente.

La apertura a la influencia externa puede adoptar diferentes formas e implicar a diferentes personas. La presencia de asesores, la realización de evaluaciones externas, la apertura de la institución a los usuarios, etc. pueden ser iniciativas que faciliten la reflexión y el análisis de lo que la institución realiza.

d) La colegialidad, frente al individualismo en el uso de estructuras y en los procesos de funcionamiento. Se atenta a este pilar cuando se potencia la fragmentación de los espacios, de los horarios, de los profesores/técnicos, de las decisiones, etc. sin establecer mecanismos de interrelación.

El desarrollo de estos pilares en la configuración de centros educativos no es un proceso sencillo, pero puede conseguirse a través de acciones que posibiliten un cambio progresivo. Desarrollar una mayor autonomía organizativa, favorecer el intercam- 
bio de experiencias y proporcionar facilitadores externos son actuaciones sugeridas que pueden posibilitar un cambio del discurso y de la práctica y que facilitan la promoción de la reflexión y la colegialidad de las instituciones.

Los diferentes integrantes de la organización toman así consciencia del compromiso de su misión y crean espacios adecuados tanto para el desarrollo personal como para el aprendizaje del saber. La respuesta a preguntas como: ¿los integrantes del centro educativo se sienten participes en un medio favorable a su desarrollo personal? $y$ ¿los alumnos tienen un encuentro productivo con el saber y una nueva forma de entender la realidad vital?, necesariamente ha de ser positiva. Y eso sólo será posible cuando los diferentes usuarios revisen, a través del estudio, reflexión y análisis crítico, lo que está aconteciendo en el interior de la institución. La organización educa, en definitiva, porque desarrolla la capacidad de los diferentes miembros de la organización en el proceso colectivo de toma de decisiones.

Pero más allá de la existencia y realización de proyectos, podemos entender como un compromiso de las organizaciones institucionalizar los cambios que progresivamente se vayan planteando. Exige todo ello la existencia de mecanismos de autoevaluación institucional y de un claro compromiso político con el cambio. La organización autocualificante, o la también llamada organización que aprende, se sitúa en un nivel que pocas instituciones alcanzan y es que instaurar, aplicar y utilizar mecanismos de evaluación en la perspectiva del cambio exige de actitudes personales y de procesos de seguimiento y evaluación que chocan con nuestra tradición y forma de hacer en las organizaciones.

Seguramente, podríamos hablar de este tercer estadio en el caso de un centro educativo que en su momento se planteó hacer efectiva una escuela para todos, lo reflejó en el Proyecto Educativo y en el Proyecto Curricular y durante años ha ido desarrollando actuaciones en esa línea. Posiblemente, ya sea un hecho asumido el incorporar a los programas y al funcionamiento de la institución algunas modificaciones que favorecen el tratamiento de la diversidad, con lo que cada vez resulta menos necesario el plantearse explícitamente esa problemática. Podemos hablar que ha habido un aprendizaje organizativo, que ha contribuido a conformar parte de la historia de la institución.

Mejorar una institución de formación en la perspectiva comentada no es una tarea fácil, pues, aparte de los problemas estructurales existentes y relacionados con la autonomía real de las instituciones, nos movemos en inercias personales e institucionales que dificultan el compromiso colectivo, el trabajo cooperativo y la autoevaluación como requisitos necesarios para la mejora.

Si consideramos a la organización que aprende' como aquella que facilita el aprendizaje de todos sus miembros y continuamente se transforma a sí misma, estamos resaltando el valor del aprendizaje como la base fundamental de la organización. El desarrollo de la organización se basa en el desarrollo de las personas y en su capacidad para incorporar nuevas formas de hacer a la institución en las que trabajan. Como ya señala Senge en su famoso texto de 1992:

1. Preferimos esta denominación a la Organización autocalificante dada por Sthal y otros (1993), por considerar que encaja más en el sentido propio que tienen las organizaciones de formación. 
"Las incapacidades para el aprendizaje son trágicas para los niños, pero fatales para las organizaciones. Por causa de ellas, pocas empresas alcanzan la mitad de la esperanza de vida de una persona y, en su mayoría, perecen antes de cumplir los cuarenta"

No todo es previsible y planificable en la vida organizacional. Hay situaciones rutinarias y relativamente fáciles de solucionar pero también las hay complejas cuya solución requiere la puesta en funcionamiento de nuevas habilidades. Se plantea así un desafío a la organización que tan sólo puede ser superado a partir del aprendizaje. Más que decidir lo que vamos a hacer en el futuro, parece necesario tomar ahora las medidas que nos pongan en condiciones de poder decidir adecuadamente cuando en el futuro sea necesario.

Las organizaciones más capaces de enfrentar el futuro no creen en si mismas por lo que son sino por su capacidad de dejar de ser lo que son, esto es, no se sienten fuertes por las estructuras que tienen sino por su capacidad de hacerse con otras más adecuadas cuando sea necesario.

"Un centro escolar no es fuerte tanto por los éxitos que ha alcanzado sino por la capacidad que pueda tener de lograr nuevos logros cuando sea necesario. Por todo ello, conseguir una organización que aprende es un propósito cada vez más valioso en los períodos de grandes cambios en el entorno escolar como los que estamos viviendo en los últimos años"

(Antúnez, 1994)

Si consideramos a la organización que aprende como aquelia que facilita el aprendizaje de todos sus miembros y continuamente se transforma a si misma, estamos resaltando el valor del aprendizaje como la base fundamental de la organización². El desarrollo de la organización se basa en el desarrollo de las personas y en su capacidad para incorporar nuevas formas de hacer a la institución en la que trabajan.

El pensar en la organización que aprende como un modelo integral de desarrollo de recursos humanos en el que todos los trabajadores de una organización se integran en un proceso de aprendizaje nos acerca a la perspectiva básica de la Calidad Total: abarca a todos y a todas las facetas de la organización.

Este marco conceptual donde se da autoaprendizaje constituye sin lugar a dudas la referencia que permite un impulso organizativo hacia el futuro. Las personas no se forman y desarrollan solamente para satisfacer los fines de la organización delimitados y prescritos sino para ampliar su función. Este planteamiento nuevo puede llegar a cuestionar aspectos relacionados con el liderazgo, la toma de decisiones y los mecanismos de control que se establecen. También obliga a explorar nuevas estrategias de aprendizaje y a modificar los sistemas de formación.

2. Bob Garret definía una Learning Organization como aquella donde existe un clima y los procesos que permiten a todos sus miembros aprender conscientemente de su trabajo, que es capaz de trasladar este aprendizaje e informacion que se necesita y que tiene a sus directivos posicionados de tal forma que pueden asegurar que el aprendizaje desde dentro y fuera es utilizado por la organización para transformarse y cambiar constantemente" (entrevista de la revista Formación y Empresa $n^{\circ} 33$, 1992:6-7) 
"La organización autocualificante tiene como objeto diseminar el proceso de aprendizaje en todos los ámbitos de la empresa e integrarlo en el funcionamiento de la misma, aunque también implica un cambio radical de las políticas organizativas, las pautas de trabajo y las metodologías de formación. Se precisa tener visión de futuro para producir estos cambios tan radicales. Una visión de este tipo articula un esbozo del futuro, que inspire a las personas a encontrar soluciones para convertir la visión en realidad. Sin embargo, una visión no es pura fantasía, sino que ha de enraizarse en la realidad y tomar en consideración los problemas y disfunciones que es preciso resolver para convertir la visión en realidad"

(Stahl y otros, 1993:XII)

\subsection{Algunas implicaciones}

La mera descripción de los diferentes estadios de desarrollo nos parece insuficiente para clarificar el verdadero sentido que tienen. Por ello, nos permitimos realizar un breve análisis de algunas implicaciones que los diferentes niveles conlleva. El cuadro 1 nos aproxima al tema.

La organización que aprende exige por su propia naturaleza de estructuras y sistemas de funcionamiento flexibles, sólo posibles cuando pensamos en un curriculum abierto. La implicación del personal que busca conlleva, asimismo, el uso de estrategias de participación y negociación coherentes con planteamientos cooperativos y con el desarrollo de roles distintos de los tradicionales. Las transformaciones también implican cambio en sus sistemas de planificación y evaluación y en el papel reconocido a los diferentes protagonistas del hecho educativo.

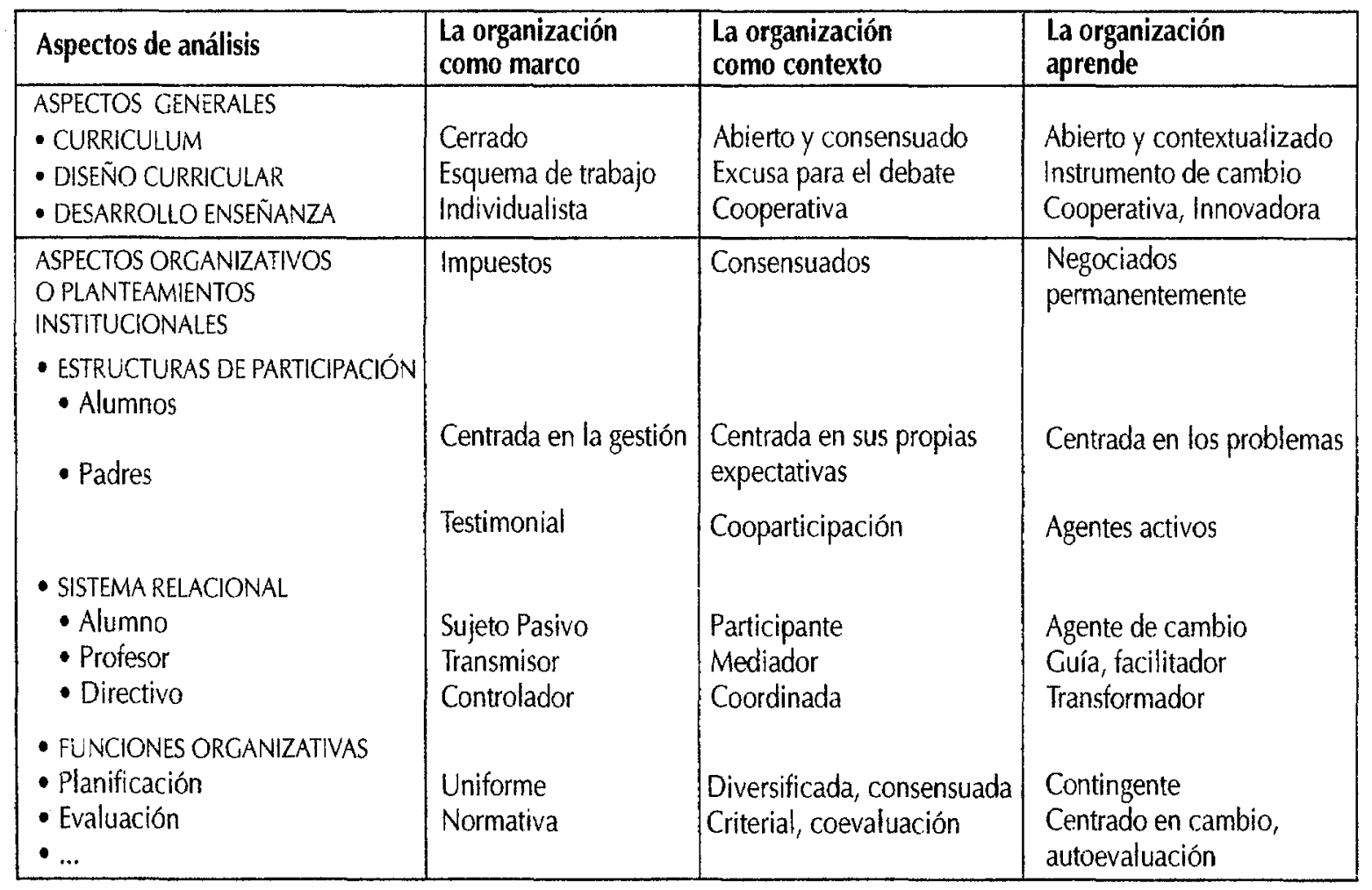

Cuadro 1. Algunas implicaciones de los diferentes niveles organizativos 
Si bien muchas de las asignaciones realizadas en el cuadro 1 son discutibles, teniendo en cuenta el valor limitado que tienen los esquemas, podemos entender como el desplazamiento hacia niveles superiores de organización conlleva transformaciones en la práctica. El gráfico 2 nos acerca a lo que podría ser el espectro que define cada una de las situaciones límite planteadas.

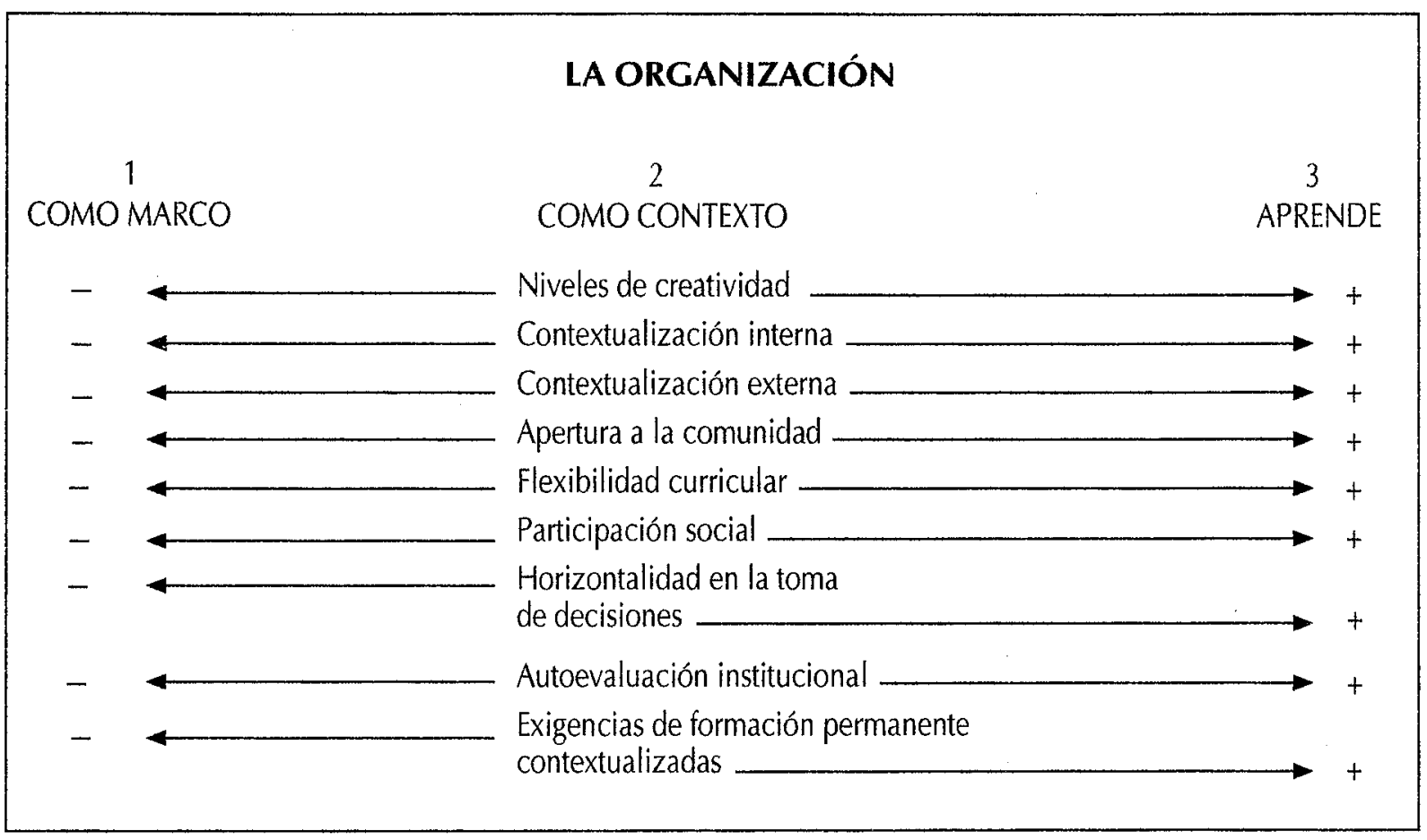

Gráfico 2. Orientaciones que adoptan las organizaciones

A los aspectos considerados en el gráfico 2 pueden añadirse otros como pudieran ser los relativos a aspectos externos (tipología de la formación permanente, papel asignado a los expertos, actividad de las instituciones de apoyo, ...), internos (implicaciones en la selección, formación y promoción de los diferentes agentes, tipología de conflictos planteados, ...) y personales (concepción de la persona que subyace, actitudes predominantes, etc.). No obstante, nos interesa resaltar más que el estudio de consecuencias el evidenciar que el paso de un estadio a otro conlleva transformaciones que afectan tanto a la enseñanza como al modelo organizativo que le ampara.

\subsection{Otras consideraciones complementarias}

Presentado el modelo en sus características generales, cabe señalar para una mejor conceptualización algunas cuestiones complementarias a las ya apuntadas. Al respecto, realizamos consideraciones referidas al modelo, a su realidad práctica y a su operativa.

El modelo se ha presentado de una forma escalar para representar que cada estadio implica el anterior; también, podría haberse hecho a partir de círculos concéntricos o de otra figura geométrica. Lo importante es entender que una organización que 
no ha ordenado su funcionamiento interno es difícil que llegue a tener capacidad formativa $y$, asimismo, a consensuar y realizar proyectos institucionales.

La realidad del modelo nos permite realizar, a su vez, algunas acotaciones:

- Aunque parezca lo contrario, no podemos decir que los estadios superiores sean mejores que los inferiores; dependerá del contexto en el que nos situemos y del grado de ordenación y desarrollo que haya alcanzado la organización. Si el contexto socio-cultural no valora el trabajo cooperativo y funciona de una manera vertical y con alto grado de individualidad, será difícil mantener una institución que defienda valores contrarios o distintos. Asimismo, mientras no se cambien actitudes individuales y protagonismos egoistas será difícil avanzar en un modelo cooperativo de funcionamiento. De hecho, podríamos decir que el nivel más adecuado para cada institución es aquel que le resulta útil en su situación actual y aspiraciones; esto es, aspirar a lo que se requiera con los recursos que se tengan.

- El avanzar a estadios más comprometedores para los usuarios de la organización se justifica bajo la perspectiva de que estos nos hacen más solidarios como personas y permiten que las organizaciones sean más eficaces al hacerse capaces de aprender de sus propios errores. Pero, dadas las posibles dificultades, ¿merece la pena avanzar?. La respuesta no puede ser más que afirmativa si pensamos lo que perdemos en caso contrario. La falta de iniciativa para potenciar un modelo de desarrollo previsible puede hacer que la organización sea obsoleta cuando los cambios necesarios se impongan desde el contexto externo. Prever los cambios y tomar iniciativas al respecto nos hace competitivos como organización.

- La realidad, sobre todo en organizaciones de muchos miembros y varios departamentos, puede suponer la presencia simultánea de varios estadios organizativos. Así, puede existir un área (administrativa, académica, actividades extraescolares, etc.) que funciona bajo el nivel 1 y otra bajo el nivel 2. Este hecho real no ha de generar problemas si la organización es consciente de la disfunción existente y promueve un cambio en el área con menor nivel de desarrollo, posibilitando mediante recursos (tiempo, espacio, formación, etc.) su evolución a un estadio superior.

- El modelo creemos que es aplicable a las organizaciones de las diferentes etapas y niveles educativos, si consideramos que la base de aquellas son siempre personas con una formación personal y profesional mínima que les permite colaborar entre si.

Desde la operativa, algunas consideraciones serian:

- El aprendizaje se realiza dentro de la organización de muchas maneras. Puede existir un programa formalizado, incluso ordenado según una propuesta de innovación, pero no cabe desdeñar el proceso de aprendizaje informal y las aportaciones que da la propia experiencia. La organización que aprende integra las diferentes vías de aprendizaje y fomenta procesos mentales identificados con ellas. El proceso de aprendizaje es continuo, no segmentado, centrado en los problemas, vinculado al contexto y afectando a todos los miembros de la organización. Lo esencial no será el aprendizaje individual, sino el aprendizaje de la organización. 
- La realización de este aprendizaje, que pasa por la implicación de las personas, supone la atención a cinco aspectos que actúan conjuntamente y que tienen que ver con las capacidades de los miembros de la organización y con las características de esta (Senge 1992):

1. Pensamiento sistémico, por el cual se integran las otras disciplinas. Haría referencia a la preocupación por los procesos y a no tratar los problemas como compartimentos estancos.

2. Dominio personal, que permite aclarar y ahondar continuamente la visión personal, y ver la realidad objetivamente. Se dirigiría a conseguir las condiciones adecuadas que permiten el desarrollo personal y profesional adecuados.

3. Modelos mentales, que tienen que ver con supuestos arraigados, generalizaciones e imágenes que influyen sobre nuestra forma de ver el mundo y actuar. Parece una exigencia la apertura mental a nuevos planteamientos y la reflexión sobre la naturaleza del trabajo y su sentido.

4. Construcción de una visión compartida, como base para el análisis y la intervención sobre la organización

5. Aprendizaje en equipo, que supone priorizar la necesidad del "dialogo" y la capacidad de los miembros del equipo para "suspender los supuestos" e ingresar en un auténtico "pensamiento conjunto".

La interrelación entre estas disciplinas se hace imprescindible y debe permitir reforzar sus actuaciones.

- Pero tan importante como la forma como se realiza el aprendizaje es el contenido y metodología. La aproximación que realizan Stahl y otros (gráfico 3) resulta bastante ilustrativa.

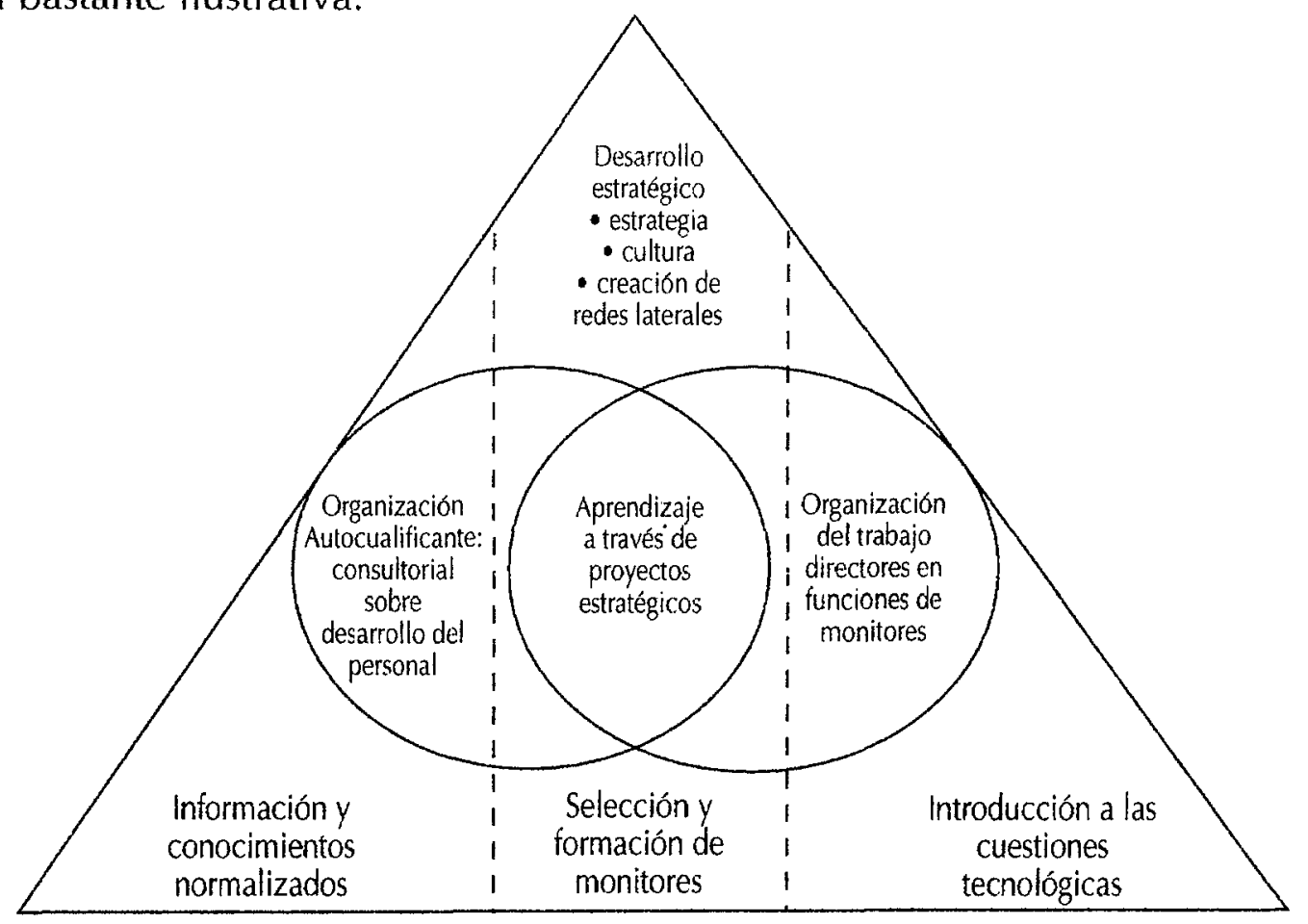

Gráfico 3: Integración del aprendizaje y del trabajo a la organización (Sthal y otros, 1993:62) 
El gráfico 3 ilustra las diferentes maneras como se puede integrar el trabajo y el aprendizaje en una organización. El área izquierda representaría una forma de hacer propia de una formación profesional tradicional o de algunos gabinetes de formación, donde el instructor desarrolla en el marco del aula contenidos normalizados de conocimiento e información. Aquí el profesor actúa de profesor, guía, moderador y facilitador del aprendizaje, además de reproducir cultura que otros han incorporado a libros de texto, videos, etc. o de producir sus propios programas.

El área derecha representa la planta de producción o el lugar de trabajo como escenario de aprendizaje. Se disminuye el modelo de formación tradicional y es preciso adaptar el lugar de trabajo al proceso de aprendizaje. El resultado es más rico, ya que la persona que se forma participa en la toma de decisiones, resuelve conflictos sociales, busca soluciones, etc. que le exigen otras capacidades que las propias del aula. También se revitaliza el valor de la experiencia y la importancia del aprendizaje autónomo.

Aparecen en este contexto las estaciones de aprendizaje, que acercan medios y materiales didácticos al puesto de trabajo. Paralelamente, los cambios en el entorno de trabajo y aprendizaje exigen de directivos que sean, a la vez, educadores y formadores.

La sección central representa la intersección de la organización del trabajo con la Organización que aprende y es aquí donde se debe producir todo el aprendizaje relevante. Los procesos de innovación y cambio fomentan la transformación de la organización y generan respuestas creativas a los factores cambiantes del entorno. La apertura a nuevas aportaciones y la forma en que se producen contribuyen a cambiar estrategias y modos de trabajo, fomentando una nueva cultura.

Aunque sea desde una visión externa a las organizaciones educativas, nos sirve para lo que mencionamos la siguiente cita que recogemos como conclusión.

"Una razón complementaria de que el lugar de trabajo sea el punto estratégico del aprendizaje es que el aprendizaje así realizado genera unos bucles de realimentación directos que conducen a la innovación de las estructuras de trabajo. La ruta ideal de la innovación en la Organización Autocualificante es la reestructuración creativa autónoma realizada por los trabajadores en sus respectivos lugares de trabajo, concepto que ya se ha implantado en muchas empresas mediante los círculos de calidad. Esta modalidad de aprendizaje en el lugar de trabajo significa igualmente la aplicación innovadora de las nuevas competencias con objeto de mejorar la eficacia en el lugar de trabajo, el departamento y la empresa en su conjunto".

(Stahl y otros, 1993:71-72)

- Se deduce de lo dicho que el requisito más importante es que exista formación y que se aplique al funcionamiento institucional. Sin embargo, esto no nos parece suficiente si la organización no sedimenta las opciones a que lleva el aprendizaje institucional. Los requisitos para la realización efectiva del proceso exige delimitar una serie de condiciones necesarias que afectan tanto a la propia formación como a sus efectos. 
Respecto a la formación a desarrollar se debe considerar su necesaria implicación a la estrategia de cambio de la organización, que conlleva una adecuada conexión entre el contenido, las metodologías de la formación y la innovación deseada. Tampoco debe menospreciarse la necesidad de desarrollar la competencia de autoaprendizaje como una cualificación clave. Asimismo, el que el entorno de trabajo se convierta en un entorno de aprendizaje, lo que exige que el trabajo se convierta en una actividad innovadora en la que hay lugar para la planificación, la toma de decisiones y una mayor autonomía para actuar Los resultados del proceso de reflexión y análisis deben llevar a cambios que sean estables y efectivos. Supone esto considerar que junto a la formación ha de darse la revisión de las prácticas, la difusión del cambio en la organización y la integración de las nuevas modalidades organizativas en una nueva cultura.

- Pero también puede pensarse en otros requisitos a partir del análisis de los elementos que configuran la organización. Las organizaciones tienen finalidades que actúan como metas tendencia; los objetivos deben ser conseguibles pero también variables en función de las necesidades institucionales. Las estructuras deben ser flexibles y también se necesita un cambio en las estructuras de poder. Se precisa disminuir drásticamente las jerarquías, creando equipos autónomos que faciliten la flexibilidad y la rapidez ante los cambios. El problema residirá ahora en lograr la coherencia entre los equipos y el no disminuir la prestancia de algunas variables organizativas (rapidez en la toma de decisiones, participación, etc.). Por último, el sistema relacional es el más afectado por el nuevo enfoque. Los cambios de concepciones, conocimientos y destrezas deben acompañarse de actitudes abiertas a la innovación.

La dirección actúa como promotora de los planteamientos de una organización que aprende $y$, en esta dirección, trata de guiarla a su transformación más que a su estricta administración ${ }^{3}$. El objetivo general no es sólo administrarla (conseguir y organizar los medios y los recursos de acuerdo a unos objetivos establecidos) sino mejorarla, rompiendo la rutina e introduciendo nuevos objetivos que permitan una actuación mejorada de acuerdo al proyecto institucional.

Las funciones organizativas cambian en este hacer pues ya no se rigen por un proceso normativo sobre como deben ser las cosas, sino más bien como posiblemente serán. Este cambio de matiz hace que la planificación normativa, que pone énfasis en los procedimientos que de manera eficiente permiten conseguir determinados objetivos ${ }^{4}$, se convierte en algo más flexible en la línea de la planificación situacional (Aguerrondo, 1993:170) o contingente (Gairín, 1992) La planificación organizativa se considera asi una sucesión de situaciones donde tiene cabida la priorización y donde se acepta que cada realidad y cada organización tiene sus ritmos, sus obstáculos y sus ventajas. Lo importante será moverse hacia la imagen-objetivo o finalidad general que queremos realizar.

3. Quizás convenga aquí recordar el texto de Gómez-Llera y Pin (1994) de título tan expresivo: Dirigir es educar.

4. Esta racionalidad está definida por los distintos pasos de su metodología: saber qué se quiere hacer (fijación de objetivos concretos), conocer la realidad y sus problemas (diagnóstico), poner en marcha las tareas (ejecución) y saber qué pasó con lo que se proponía (evaluación). 
- Otras cuestiones operativas se relacionan con el cambio que se pretende desarrollar y con los modelos coherentes con el mismo. Al respecto, se pueden plantear diversas cuestiones:

- ¿Qué condiciones permiten que una organización pase de un estadio a otro?

- ¿De dónde puede surgir el cambio: iniciativa de los técnicos, de la titularidad, ...?

- ¿Qué protagonismo pueden crear las exigencias externas: sociales, laborales, políticas, ...?

- ¿Cómo influye la priorización de lo político sobre lo académico en los diferentes niveles?

- ¿Cómo explicar los cambios que se producen? ¿Cómo explicar la ausencia de cambios pretendidos y no conseguidos? ¿Qué resistencias al cambio aparecen?

- ¿Puede considerarse tan importante la voluntad política del cambio como la existencia de una mínima planificación? ¿Qué rol juegan los directivos al respecto?

- ¿Cuál debería ser la formación para el cambio? ¿Cómo habría que fomentar la implicación en el cambio?

- etc.

Como vemos, son muchas las cuestiones que enlazan el tema que analizamos con las posibilidades reales de transformar la práctica.

\section{Concepciones y estadios de desarrollo organizativo}

La evolución histórica de la Organización Escolar como constructo científico y el conjunto de factores que la han conformado como disciplina explican la existencia de diversas tendencias. La variedad de enfoques conceptuales y terminológicos bien pudieran dar la razón a Harold Koontz cuando habla de la selva de la teoría administrativa. El amplio desarrollo de teorías existente justifica la afirmación de que el campo organizativo está en un momento de reconceptualización, reflejando quizás más tardíamente los problemas, perspectivas y teorías que también afectan al campo de las Ciencias Humanas y de las Ciencias Sociales.

En estas circunstancias, centramos nuestro análisis en conceptualizaciones globales, que nos permitan simplificar el ámbito de estudio y orientar, posteriormente, una mayor profundidad. Se justifica así la búsqueda de planteamientos globales que permitan clarificar tendencias $y$, en todo caso, aportar explicaciones más generales que las propias de una teoría específica.

Siguiendo el camino iniciado por Habermas (1982) respecto a las estructuras de racionalidad y la aplicación que ya se hizo al campo organizativo (Gairín, 1986), podemos plantearnos si ipuede existir relación entre los diferentes enfoques y los niveles de desarrollo organizacional planteados?

Nuevamente el peligro es la simplicidad. Pero aún asumiéndola podemos encontrar un cierto paralelismo entre los análisis efectuados, tal y como se recoge en el cuadro 2. 


\begin{tabular}{|l|l|l|}
\hline \multicolumn{1}{|c|}{$\begin{array}{c}\text { NIVELES DE DESARROLLO } \\
\text { ORGANIZACIONAL }\end{array}$} & $\begin{array}{c}\text { VISIÓN DE LA } \\
\text { ORGANIZACIÓN }\end{array}$ & $\begin{array}{c}\text { ENFOQUE } \\
\text { ORGANIZATIVO } \\
\text { COHERENTE }\end{array}$ \\
\hline La organización como marco & $\begin{array}{l}\text { - Estructura de soporte } \\
\text { - Marco limitado }\end{array}$ & Científico - racional \\
\hline La organización como contexto & $\begin{array}{l}\text { - La organización educa } \\
\text { La organización puede ordenarse } \\
\text { a partir de un proyecto común }\end{array}$ & Interpretativo - simbólico \\
\hline La organización aprende & $\begin{array}{l}\text { - La organización es capaz de } \\
\text { aprender } \\
\text { La organización contribuye a } \\
\text { transformar la realidad }\end{array}$ & Socio-crítico \\
\hline
\end{tabular}

Cuadro 2. Enfoques y estadios de desarrollo organizativo

El interés que pone el enfoque científico-racional por estructurar la realidad de una manera "mecánica" es coherente con el papel asignado a la organización como marco. Se le pide a esta que estructure la realidad de acuerdo a una lógica externa (exigencias internas o externas del currículum) sin tener en cuenta los intereses de las personas implicadas.

La preocupación del enfoque interpretativo-símbólico por las percepciones, expectativas $u$ otras dimensiones internas de las personas resulta ser una base imprescindible para realizar el trabajo colaborativo que exige una organización que quiera ordenarse como contexto que también educa. Asumir este estadio supone, asimismo, entender que el cambio es eminentemente cultural.

Por último, parece imposible lograr el estadio donde la organización aprende si no se asumen planteamientos relacionados con la autoevaluación, el estudio de intereses, los niveles de consenso, el conflicto, etc. propios de un enfoque más socio-crítico.

Pero más allá de la identificación realizada, no podemos dejar de manifestar la posibilidad real de que en un mismo centro educativo puedan convivir varios enfoques organizativos, aunque exista uno dominante. Sucede, por ejemplo, cuando la dirección aplica sistemas de funcionamiento tecnocráticos, mientras los departamentos didácticos funcionan con planteamientos culturales y/o socio-críticos (actúan colaborativamente, realizan procesos de autoevaluación, ...).

$Y$ es que la realidad suele ser más compleja que los modelos que la intentan explicar. El hecho de hablar de orientaciones diferentes no debe llevarnos necesariamente a considerarlas enfrentadas. Se trata más bien de distintos niveles de análisis que la perspectiva histórica ha ido evidenciando. Es más, podríamos aventurar la hipótesis de que son abarcadoras y complementarias.

Cada nivel de análisis supone una conceptualización más amplia que permite una mayor profundidad en el estudio de la organización. Si los planteamientos calificados de racionales se plantean la organización en sus manifestaciones, los simbólicos lo hacen en su realidad y los críticos profundizan en las razones de esa realidad.

Por otra parte, es difícil pensar que pueda plantearse una perspectiva crítica sobre una realidad aún no conocida. Los paradigmas científico-racional e interpretativosimbólico aportan, en tal sentido, la materia prima para la elaboración del paradigma crítico. De igual modo, los simbolismos de una organización no son totalmente abs- 
tracciones puras sino que se fundamentan en estructuras conocidas y en propósitos manifestados por las organizaciones.

Bajo este análisis, podemos entender que en una realidad organizativa pueden convivir los tres estadios de desarrollo considerados. Puede suceder que no haya una orientación clara al estadio 2 (organización como contexto) ó 3 (organización que aprende) y, sin embargo, haya áreas de la organización (académica, administrativa, ...) u órganos (departamentos, equipos de ciclo,...) que se hayan situado a esos niveles.

Queda así patente que la realidad escolar no sólo es un sistema complejo y distinto respecto a otras organizaciones, también lo es multifacético y multidimensional. Hablamos de multifacético en la medida en que puede ser analizado desde diferentes ámbitos (sistema de objetivos, sistema estructural y sistema relacional), pero también caben múltiples perspectivas en cada uno de ellos, como evidencian, los enfoques analizados y sus múltiples implicaciones.

\section{Modelo educativo, modelo de enseñanza y estadios de desarrollo organizativo}

Los estadios de desarrollo organizacional pueden relacionarse, más allá de sus implicaciones generales de tipo organizativo, con las diferentes formas como se han entendido y entiende el hecho educativo. El cuadro 3, pese a poder caer en simplificaciones, puede representar una aproximación a las vinculaciones existentes.

\begin{tabular}{|c|c|c|c|c|}
\hline $\begin{array}{l}\text { NIVELES DE DESARROLLOO } \\
\text { ORGANIZATIVO }\end{array}$ & $\begin{array}{l}\text { PARADIGMAS } \\
\text { EDUCATIVOS }\end{array}$ & $\begin{array}{c}\text { PARADIGMAS DE } \\
\text { ENSEÑANZA APRENDIZAIE }\end{array}$ & $\begin{array}{l}\text { TIPOLOGIAA } \\
\text { PROFESIONAL }\end{array}$ & $\begin{array}{l}\text { MODELO DE } \\
\text { FORMACIÓN }\end{array}$ \\
\hline $\begin{array}{c}\text { LA ORGANIZACIÓN } \\
\text { COMO MARCO } \\
\end{array}$ & Tecnológico & $\begin{array}{l}\text { - Presagio - producto } \\
\text { - Proceso - producto } \\
\end{array}$ & Técnico & $\begin{array}{l}\text { Cultural } \\
\text { Competencial }\end{array}$ \\
\hline $\begin{array}{l}\text { LA ORGANIZACIONN } \\
\text { COMO CONTEXTO }\end{array}$ & Cultural & $\begin{array}{l}\text { - Mediacional centrado } \\
\text { en el profesor } \\
\text { - Mediacional centrado } \\
\text { - en el alumno } \\
\text { - Mediacional mixto } \\
\end{array}$ & $\begin{array}{l}\text { Técnico } \\
\text { colaborativo }\end{array}$ & $\begin{array}{l}\text { Humanista } \\
\text { Personalisla }\end{array}$ \\
\hline LA ORGANIZACIÓN APRENDE & Socio-crítico & $\begin{array}{l}\text { - Ecológico } \\
\text { - Crítico - contextual }\end{array}$ & $\begin{array}{l}\text { Transformador } \\
\text { social }\end{array}$ & $\begin{array}{l}\text { Ideológico } \\
\text { Técnico - crítico }\end{array}$ \\
\hline
\end{tabular}

Cuadro 3: Educación, enseñanza, formación y niveles de deastrollo organizativo

Entender la organización como marco es situarla en una posición de mero soporte de la enseñanza. Esta perspectiva es coherente con un enfoque educativo tecnológico que considera al proceso educativo como un problema técnico solucionable a partir de un buen esquema de trabajo. También es coherente con enfoques de enseñanza centrados en el producto a conseguir, aunque varíe la consideración que se da a los elementos intervinientes (cualidades del profesor en el enfoque presagio-producto y conductas de enseñanza en el enfoque proceso-producto).

Subyace en el modelo la idea de profesionales como meros técnicos y es consecuente con una formación centrada en conocimientos (modelo cultural) o en la adquisición de determinadas competencias (modelo competencial).

Este enfoque, basado en el paradigma conductual, mantiene una concepción muy mecánica de la realidad, lo que permite acusarlo, sin dejar de considerar su utilidad 
en algunos aspectos, de descontextualizado, de despersonalizado y de tendencia a la programación rígida y tecnocrática.

La concepción de la organización como contexto enlaza con la idea de la realidad como construcción intersubjetiva, que da importancia a los procesos por encima de los productos. A nivel de enseñanza ha supuesto la incorporación de diseños de tres factores y la incorporación de procedimientos cualitativos de análisis de datos, dando entrada a los llamados planteamientos cognitivos.

El comportamiento observable ya no es objeto de una consideración exclusiva, es el resultado observable de un proceso de pensamiento del profesor/alumno donde inciden los conocimientos previos, las disposiciones personales, las formas de procesar y utilizar la información, así como sus percepciones y expectativas. La traslación del interés del comportamiento observable al pensamiento latente incluye una concepción de la enseñanza como un proceso de resolución de problemas en un contexto turbulento en el que no tienen sentido los comportamientos y estilos de actuación prefijados.

Desde este planteamiento, el profesor es un constructivista que contínuamente elabora y comprueba su teoría personal del mundo. Se da y busca un cierto compromiso entre el pensamiento/previsión y la acción/compromiso. Se entiende que la enseñanza es básicamente un proceso de comunicación interpersonal y, por ello, el objetivo primordial de la formación del profesorado es el desarrollo y plenitud de su personalidad. Convertirse en un buen profesor no es tan sólo, para esta concepción, aprender a enseñar, es sobre todo una cuestión de descubrimiento personal, de aprender a usar bien el propio yo. Así, los programas de formación deben referirse a personas, más bien que a competencias. Se trata de formar personas creativas, capaces de moverse y de cambiar de acuerdo a las circunstancias. Coherentemente, y frente al modelo anterior que busca una formación estandarizada mediante modalidades de cursos, enseñanza a distancia, etc., se trata de potenciar una formación en el centro educativo que parta del intercambio de experiencias propias.

Por último, la idea subyacente a la organización que aprende enlaza, por lo menos en su filosofía, con una concepción educativa y de la enseñananza que tiene en cuenta el carácter multidimensional y multifacético de la realidad. Se parte de las concepciones anteriores pero se integran en el marco de los intercambios sociales que se dan dentro y fuera de la institución. Hay una preocupación por variables situacionales y por el dinamismo de la realidad que no se da en los anteriores enfoques.

La unidad de acción que es el aula o el centro, sujeta a influencias internas y externas, es el foco de atención del profesor y de la formación que se ha de dar. Se trata de proporcionarle recursos para que, además de transmisor cultural, sea un transformador a partir del diagnóstico/observación de la realidad, del establecimiento constante de controles y del desarrollo de la crítica sobre la toma de decisiones que exija la realidad.

Coherentemente, la formación ha de permitir no sólo conocer como se ha de desarrollar la enseñanza sino debatir el porque se ha de hacer de una manera determinada, lo que supone legitimizar al profesor por la posesión de un conocimiento crítico que le sitúa en una posición de intelectual ante el fenómeno educativo y sus implicaciones sociales. 
Frente al modelo competencial puro, concreción de un enfoque de la enseñanza del tipo proceso-producto, se defiende aquí la competencia epistemológica; esto es, no saber sólo las cosas sino las razones de que sean de una u otra manera.

Admitimos, pues, una cierta relación entre las diferentes variables analizadas. No obstante, queremos resaltar que ni las relaciones pueden considerarse lineales y excluyentes, ni en la realidad existe esa categorización. De hecho, podríamos establecer un esquema explicativo de la complejidad como el presentado en el gráfico 4 .

Los grados de atención a aspectos de la enseñanza varían en función del nivel de desarrollo organizativo que se considere pero, en cualquier caso, suele haber una consideración, aunque sea mínima, a los diferentes aspectos. Así, para las organizaciones que aprenden llama la atención las exigencias del entorno, aspecto infravalorado, frente a las exigencias personales internas, en la organización como contexto.

Concluyendo, podemos decir que un modelo mixto que considera los diferentes aspectos de la enseñanza puede ser aceptable como propuesta pero no logra evitar el debate sobre el equilibrio interno que debe existir entre los diferentes aspectos; en definitiva, no se elimina la opción ideológica.

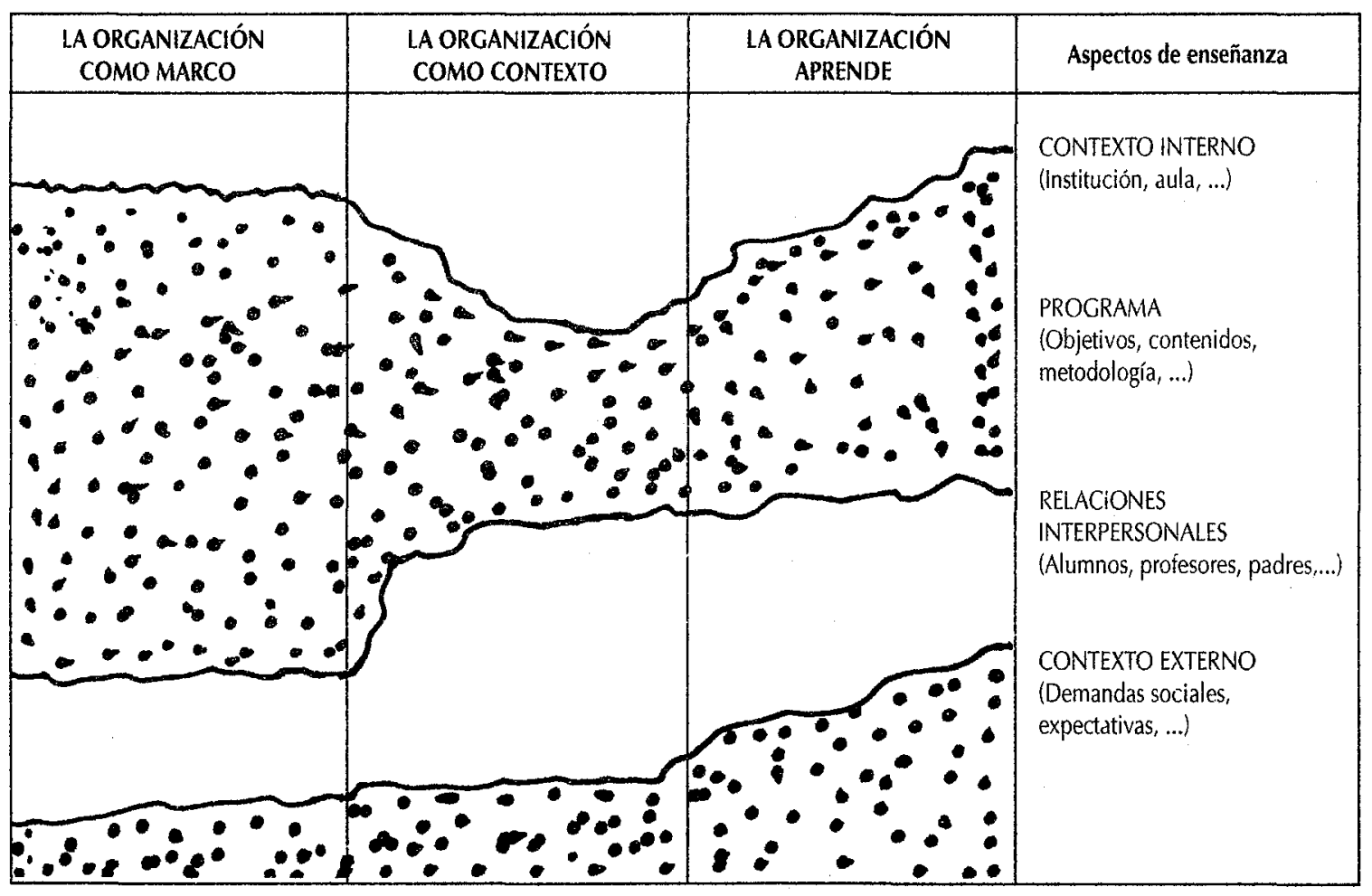

Gráfico 4: Relaciones entre los diferentes elementos a la hora de organizar la enseñanza

\section{La organización como contexto y texto para un proyecto de calidad educativo. El estadio dos.}

Si realizamos una evaluación global del desarrollo organizativo existente en nuestros centros educativos, podemos comprobar como la mayoría se mueven en el primer estadio organizativo. No sólo conciben la organización en la práctica como un 
soporte de la enseñanza sino que muchas veces no logran que sea un soporte de calidad. Sucede esto cuando el profesor de aula tiene que preocuparse de localizar medios didácticos, de gestionar excursiones o de ordenar recursos, distrayéndose de su tarea principal que es la enseñanza.

Superar esta situación y hacer de la organización una buena estructura de soporte que facilite y potencie el desarrollo del curriculum, es un reto a conseguir; el segundo sería el pasar a un estadio superior, que exige de nuevas estructuras y de un cambio en las estrategias de funcionamiento.

Situados en el segundo estadio, al considerar que es el reto que muchos centros educativos pueden plantearse actualmente, revisamos algunas de las condiciones que posibilitan el cambio efectivo. Básicamente, consideramos como imprescindibles:

- establecer estructuras de apoyo al desarrollo del curriculum,

- fomentar planteamientos colaborativos, y

- reconocer y utilizar estrategias de dinamización adecuadas, a las que dedicamos unas breves notas.

\begin{tabular}{|c|c|c|}
\hline NIVELES ORGANIZATIVOS & CONSECUENCIAS ESTRUCTURALES & ESTRUCTURAS DE FUNCIONAMIENTO \\
\hline LA ORGANIZACIÓN COMO MARCO & Importancia de las estructuras verticales & Por disposiciones dictadas \\
\hline LA ORGANIZACIÓN COMO CONTEXTO & $\begin{array}{l}\text { Aparición de las estructuras de apoyo } \\
\text { (equipos de profesores) }\end{array}$ & Por consensos previos \\
\hline LA ORGANIZACIÓN APRENDE & $\begin{array}{l}\text { Integración de las estructuras verticales } \\
y \text { de apoyo (círculos de calidad) }\end{array}$ & $\begin{array}{l}\text { A partir de disfunciones detectadas } \\
\text { mediante la evaluación }\end{array}$ \\
\hline
\end{tabular}

Cuadro 4: Niveles de desarrollo y consecuencias organizativas

Hacemos así referencia a la implantación de estructuras de apoyo a lo pedagógico, la potenciación de procesos cooperativos y la utilización de estrategias de acción claramente diferenciadas de las tradicionales, en el marco de la potenciación de una cultura colaborativa.

El desarrollo de equipos de profesores dirigidos a planificar, desarrollar y evaluar conjuntamente la acción educativa se vincula directamente a la mejora de la enseñanza. Los departamentos didácticos (responsables de la coordinación vertical de los procesos de enseñanza-aprendizaje) y los equipos educativos (responsables de garantizar la unidad de acción y el respeto de las peculiaridades de cada alumno), considerados como órganos de apoyo y complementarios, son su expresión más característica.

La importancia organizativa de los departamentos didácticos y de los equipos educativos reside en sus propios objetivos como órganos "staff". Estos pretenden, al decir de Riccardi (1965):

1. Conseguir el máximo rendimiento del personal del centro.

2. Facilitar a los miembros de la organización el patrimonio de habilidad y experiencia que hay en la empresa educativa. 
3. Favorecer la incorporación a la institución educativa, en beneficio de todos, del mismo patrimonio individual de experiencia y de ideas adquiridas en otros lugares.

4. Hacer que todos puedan aprovechar los métodos, los descubrimientos científicos, las nuevas actitudes y los nuevos puntos de vista desarrollados en los últimos años o que se prevean fundamentales los próximos años.

A las asignaciones realizadas podemos añadir algunas otras como:

5. Mejorar las actitudes y las actuaciones del profesorado de cara a una renovación.

6. Potenciar la promoción profesional, abriendo vías que la posibiliten.

7. Mejorar los sistemas y los métodos de organización.

8. Hacer posible un rendimiento más alto de los recursos humanos, materiales y funcionales del centro.

La consecución de estas metas hace necesario prestar atención a los ámbitos de actuación recogidos en el gráfico 6 y desarrollados de forma más concreta en los cuadros 5 y 6.

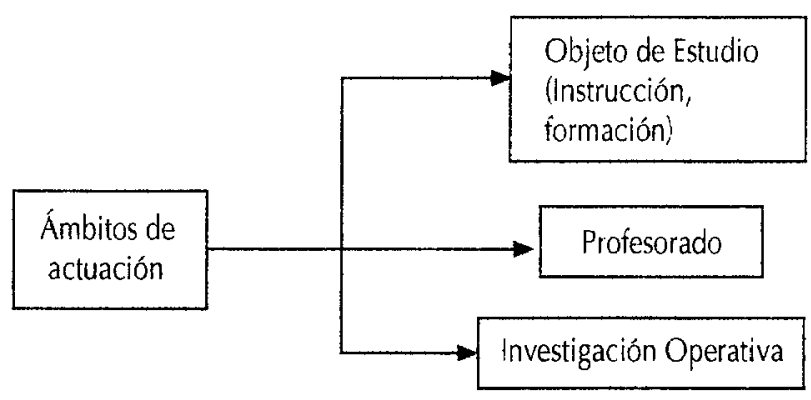

Gráfico 6: Ámbitos de actuación de los departamentos didácticos y equipos educativos

La atención al objeto de estudio (proceso de enseñanza-aprendizaje o formación) permite mejorar la coherencia interna de las actuaciones. La atención al profesorado parte del supuesto de que toda mejora educativa no sólo se vincula a un buen programa, sino que también es consecuencia de la actuación e implicación de las personas que lo han de realizar. Fomentar el intercambio de experiencias entre los profesores, hacer que asistan a jornadas y congresos, llevar a cabo seminarios de formación internos y externos, etc. ha de contribuir, sin duda, al perfeccionamiento del profesorado.

Finalmente, la investigación aplicada contribuye a modificar la práctica educativa mediante la reflexión sobre experiencias concretas, convirtiéndose en un motor que dinamiza la actuación del profesorado y, al mismo tiempo, permite solucionar los problemas que plantea el proceso de enseñanza-aprendizaje.

Los departamentos didácticos y los equipos educativos considerados como estructuras deseables a conseguir, no son las únicas. La historia y las posibilidades operativas de los centros educativos determinan la existencia de estructuras intermedias. Los equipos de ciclo pueden considerarse como una estructura de este tipo, ya que, a menudo, intervienen tanto en el campo instructivo como en el formativo. En el primer caso, actúan como departamentos didácticos y en el segundo, como equipos educativos. No obstante, el cumplimiento efectivo de las dos funciones puede suponer una 
pérdida de tiempo, y, al mismo tiempo, no elimina la necesidad de una coordinación entre ciclos. Por otra parte, un funcionamiento muy potenciado y autónomo de los equipos de ciclo puede hacer perder la unidad de actuación general del centro e impulsar intereses particulares de los ciclos.

Consideramos a los equipos de ciclo, por tanto, como estructuras de transición que tendrán que evolucionar progresivamente y adquirir las funciones de los equipos educativos, facilitando así la formación de los departamentos didácticos en el caso de enseñanza primaria. La enseñanza secundaria que ya tiene establecidos los departamentos didácticos deberá potenciar, por el contrario, los equipos de ciclo y de nivel que faciliten la coordinación de los profesores que incidan en un mismo grupo de alumnos.

\section{A. Referidas a la materia.}

\section{A.1. Generales:}

- Elaboración y aplicación del plan de trabajo anual

- Unificación de criterios y coordinación de actuaciones didácticas.

- Determinación de los criterios generales de programación.

- Supervisión de las programaciones y de su aplicación.

- Evaluación periódica del grado de eficacia de los programas.

- Coordinación con los equipos educativos.

- Autoevaluación de su funcionamiento.

- Redacción y revisión de la normativa del departamento.

- Orientación metodológica del profesorado

- Supervisar y controlar servicios propios (biblioteca, laboratorio, etc.).

A.2. Relativas al diseño instructivo

A.2.1. Objetivos:

- Determinar los objetivos generales de la materia de aprendizaje.

- Determinar los objetivos generales por niveles de aprendizaje.

- Diferenciar los objetivos mínimos y complementarios de ciclo y nivel.

A.2.2. Contenidos.

- Determinar los contenidos básicos, de ampliación y de recuperación.

-

A.2.3. Material

- Realizar propuestas de organización del material específico

- Proponer y priorizar compras de material didáctico

- Determinar el material del alumno y proponer criterios para la selección del específico de la materia.

- Orientar la elaboración de material específico para la materia.

- Inventariar material y controlar la biblioteca técnica.

A.2.4. Actividades

- Confeccionar matrices de actividades.

- Proponer modelos de actividades.

- Proporcionar experiencias de globalización, interdisciplinariedad...

- Determinar actividades complementarias.
A.2.5. Metodología.

- Coordinar los procesos metodológicos.

- Reflexiones sobre las metodologías y proponer las más adecuadas.

- Determinar los niveles de dificultad de la materia y las estrategias para abordarla.

- Proponer elementos motivacionales.

- ..........

A.2.6. Evaluación.

- Proponer y unificar criterios sobre el modo de evaluación.

- Proponer criterios sobre el contenido de la evaluación.

- Elaborar pruebas diagnósticas sobre contenidos.

- Analizar y tipificar pruebas de control.

- Evaluar los elementos del diseño instructivo.

- Analizar y evaluar las estrategias docentes.

- ..........

B. Referidas al profesorado (buscan su perfeccionamiento didáctico y técnico).

- Intercambio de opiniones y experiencias en el departamento.

- Autoevaluación de las actuaciones del profesorado (microteaching, diarios de clases, relatos, ...)

- Seminarios internos de formación: expertos del centro o externos, grupos de trabajo...

- Seminarios externos de formacion: cursos, seminarios, congresos...

- Participación en programas específicos de formación permanente.

- Control, análisis y publicación de experiencias.

- Información sobre temas de interés científico.

- Información general sobre cursos, seminarios, etc., de interés didáctico.

C. Referidas a ambos (investigación operativa).

- Investigación sobre el contenido de la materia.

- Estudios sobre diversas metodologías y resultados de su aplicación.

- Revisión y experimentación de técnicas instructivas.

- Validación y fiabilización de pruebas de rendimiento.

- Experimentación de nuevas formas de organización del profesorado y alumnado.

- Participación en investigaciones curriculares.

- Creación y utilización de recursos.

Cuadro 5: Tareas propias de un departamento didáctico (Gairín, 1986) 


\section{Como órgano ejecutivo}

- Aplicación del reglamento de régimen interior y otras normas.

- Elección del coordinador.

- Adscripción del grupo de profesores.

- Organización interna del grupo de profesores.

- Agrupamiento de alumnos.

- Unificación de criterios y prácticas académicoadministrativas.

- Distribución de tiempos (módulos horarios) y espacios.

- Propuesta de asignaciones presupuestarias.

- Distribución, mantenimiento y cuidado del material del ciclo.

\section{Como equipo educativo}

A. Referidas directamente a la formación del alumno.

A.1. Generales

- Unificación de criterios y coordinación de actuaciones formativas (disciplina, integración, dificultades de aprendizaje...).

- Planificación y realización de actividades educativas conjuntas (salidas, festivales...).

- Colaboración y coordinación con otros centros, órganos de apoyo (EAPS, departamento de orientación...) e institucionales locales o supralocales con finalidades educativas (esplais, casas de colonias...).

- Autoevaluación de sus acciones.

-

A.2. Organizativas.

- Coordinación de actuaciones con otros ciclos.

- Coordinación de las actuaciones de los departamentos didácticos y del departamento de orientación.

- Coordinación de actuaciones escolares y extraescolares.

- .........

A.3. Curriculares.

- Coordinación instructiva de carácter horizontal (metodología, actividades de globalización...)

- Información bidireccional con los departamentos.

- Estudio y planificación de hábitos y técnicas.

- Mejora positiva de actitudes y motivaciones.

- Evaluación formativa.

- Proponer actividades complementarias.

\section{A.4. Alumnos}

- Seguimiento de la dinámica de los grupos-clases.

- Estudio y seguimiento de casos individuales específicos.

- Coordinación de criterios para el registro sistemático de actuaciones.

- Propuesta de permanencia de un año más en el ciclo.

- .........

Padres.

- Criterios generales de información y actuación (reuniones, entrevistas...)

- Establecimiento de vías de comunicación personales e institucionales.

- Colaboración en la realización de actividades formativas.

- .........

B. Referidas a las personas que intervienen (formación interna).

- Intercambio de opiniones sobre la problemática educativa del centro.

- Intercambio de experiencias y valoraciones con otros centros cercanos.

- Seminarios internos de formación (expertos del centro o externos, grupos de trabajo...).

- Participación en cursos y seminarios de formación psicopedagógica.

- Asistencia a congresos, jornadas, seminarios, etc.

- ........

C. Referidas a ambos (investigación operativa).

- Análisis de modelos de informes, entrevistas, historial del alumno...

- Validación de pautas de observación, pruebas psicotécnicas.

- Experimentación de nuevas formas de agrupamiento de profesores y/o alumnos.

- Estudios sobre aspectos con incidencia formativa (disciplina, formación y trabajo de grupos...).

- Participación en planes experimentales curriculares y organizativos.

- Autoevaluación de aciuaciones del profesorado ("microteaching", relatos...).

- Revisiones bibliográficas.

\section{Cuadro 6: Tareas propias de un equipo educativo (Gairín 1986)}

Sea cual sea la estructura cooperativa implantada, no debemos olvidar la importancia de que estas estructuras combinen en su funcionamiento los tres referentes señalados al definir sus funciones: mejora del programa, perfeccionamiento del profesorado e investigación. Así, la mejora del sistema de evaluación de aprendizajes (programa), debería ir acompañada de un análisis de lo que se hace (investigación operativa) o de lo que se puede hacer (formación permanente del profesorado)

La potenciación de los procesos cooperativos exige la creación de una nueva cultura que rompa con el esquema de individualización y balcanización aún vigente. La búsqueda de centros educativos de calidad parte de la convicción de que es posible crear, conservar y transformar la cultura, a pesar de que se requieran tiempos largos, para adecuarla a las nuevas exigencias. Entiende que el hecho de compartir concep- 
ciones y convicciones sobre la enseñanza y el papel de los profesores es fundamental para lograr acciones coordinadas y de calidad.

El tipo de cultura a desarrollar coincidiría con la cultura participativa mencionada por San Fabian (1992):

"un centro con cultura participativa es aquel donde las normas y valores democráticos son ampliamente compartidos, se expresan en sus documentos y guían la conducta, se refuerzan regularmente mediante recompensas y desde la dirección. En este caso se cumplirían algunos requisitos como mejorar la implicación de los padres; no descuidar la imagen del centro; una buena comunicación y coordinación entre las unidades de la organización; un liderazgo que apoya los procesos participativos, democrático y pedagógico; ayudar y apoyar los grupos de trabajo en el centro; agotar las posibilidades de consenso en los procesos decisionales."

Se trata de identificar a los miembros de la organización con el proyecto institucional, de compartir su estrategia de trabajo, de implicarse en su consecución y de sentir la necesidad de evaluar las actuaciones para ver si la mejora se da en la dirección señalada.

La potenciación de una cultura peculiar y consolidada permite orientar las acciones individuales y colectivas, movilizando una buena parte del potencial personal y profesional de los componentes de la organización. El cambio apoyado en una cultura consecuente es el más eficaz y duradero, aunque, sin ninguna duda, es el más difícil de conseguir.

Es, por tanto, un cambio promovido desde dentro a partir de las propias inquietudes y necesidades lo que se pretende, sin que ello elimine la posibilidad de contar con ayudas externas. Es también un cambio que debe partir del análisis de la cultura existente, del estudio de las razones que llevan a su instalación y a su cambio y de la selección de las estrategias más adecuadas a un determinado contexto.

El desarrollo de esta cultura común debe apoyarse en la actuación de un fuerte liderazgo instructivo que considera los factores de calidad y que dinamiza al centro educativo. Atiende por otra parte, al efecto y consecuencias que puede tener el desarrollo de culturas contrarias a la mejora o a los compromisos institucionales.De hecho, se trata de reconocer las aportaciones de enfoques críticos que enfatizan en el peligro de la uniformidad que elimina cualquier posibilidad de manifestar y reproducir los intereses que siempre existen.

El liderazgo instructivo mencionado agrupa el conjunto de actuaciones desarrolladas para conseguir un ambiente de trabajo productivo y satisfactorio para los profesores y condiciones y resultados de aprendizaje deseables para los alumnos. Las dimensiones que tiene que atender son presentadas por González (1991) y recogidas sintéticamente por nosotros a continuación:

a) Definir la misión de la escuela

- Establecimiento de metas claras y explicitas, que también abarcan los procesos de enseñanza-aprendizaje.

- Interés por la mejora del programa escolar. 
- Implicación en la definición y logro de metas de diferentes agentes y fuentes: necesidades alumnos, exigencias administración, interés de los padres,...

- Lograr consenso respecto a las metas y metodologias para lograrlas.

b) Gestión instructiva

- Dedicar tiempo a la coordinación curricular.

- Atender las variables organizativas que faciliten / dificulten el trabajo en las aulas: proteger el tiempo de enseñanza, atender la asignación de profesores, posibilitar la atención a grupos / alumnos, unificar criterios escolares y para escolares.

c) Promover un clima de aprendizaje positivo

(construir y sostener un clima y cultura de colaboración)

- Promover acciones de participación de profesores: delegar autoridad, compartir decisiones, establecer equipos de profesores,...

- Motivar a los profesores a que lo hagan mejor: participación en metas, compromisos de acción,...

- Implicarse en actividades con los profesores.

- Fomentar relaciones interpersonales profesionales: proporcionar información, compartir problemas,...

- Promover el acceso del profesorado a actuaciones que permitan el desarrolo profesional.

- Potenciar la coordinación con otros profesionales que también trabajen con alumnos.

No podemos olvidar, por último, que el Jefe de Estudios es miembro de un Equipo Directivo que debe promover como sistema la mejora y que se enfrenta, precisamente ahora, con un proceso de cambio promovido por el sistema educativo. Al respecto, debemos pensar en el como:

a) Promotor de una cultura corporativa, que implica:

- Considerar a la organización como un medio formativo.

- Transmitir en todas las actuaciones un sentido de identidad.

- Impulsar los compromisos personales y la máxima coherencia de expectativas y percepciones.

- Reconciliar los valores organizacionales (nomotéticos) y los valores personales (ideográficos).

b) Gestor del cambio, lo que exige la atención a:

- Perfeccionamiento de profesores vinculado a programas específicos.

- Desarrollo del papel y funciones de sus colaboradores como líderes de la enseñanza.

- Establecimiento de nuevos valores compartidos y normas facilitadoras de la acción colectiva.

En definitiva, servir de soporte técnico, de medio para alcanzar infraestructura y de elemento de promoción de la moral de los grupos. (Gairín, 1993) 
c) Impulsar una institución creadora e innovadora, que al decir de la O.C.D.E., supone:

- Horizontalidad y colegialidad frente a jerarquización.

- Toma de decisiones participativa.

- Comunicación abierta y libre.

- Estructura flexible en normas y valores.

- Proporcionar recursos para quien los precisa.

Se trata, en definitiva, de fomentar la creación de contextos abiertos, poco formalizados donde las cortapisas de entrada sean mínimas y las posibilidades adaptativas amplias. Por ello, los

"directores han de trabajar para establecer nuevas normas que recompensen la planificación colaborativa, la enseñanza abierta a discusión, el feed-back constructivo y la experimentación. El desarrollo profesional ha de ser considerado como algo valiosos y posible. Donde más ha florecido la estrategia 'coaching', los directores han asumido roles activos para ayudar a los grupos, para apegarlos, suministrando tiempos para reuniones de intercambio de planes y enseñanza y facilitando ayudas a los coordinadores de equipo" (Showers, 1985:45)

Por último, cabe recordar la coherencia de usar estrategias de intervención adecuadas a la cultura colaborativa que se persigue y a la naturaleza de las estructuras que se quieren potenciar. Todos admitimos que la intervención orientada bajo los presupuestos de una actuación realista, sistemática y progresiva debe ir dirigida a potenciar la calidad de la educación, a facilitar un contexto que también eduque y a favorecer el crecimiento de la organización. Sin embargo, el problema ya no reside tanto en saber qué perseguimos como en definir la forma de logarlo.

Como dice McKanzie:

"Es tal el nivel de consenso sobre cuáles son los factores principales de la eficacia de la escuela que la cuestión sobre qué es importante para esa eficacia quizás sea ahora menos significativa que la cuestión sobre qué puede cambiarse a un menor precio y con los mejores resultados"

(cit López, 1994:104)

Hay que enfatizar, por tanto, en las estrategias y junto a ellas en las actitudes que mantienen los implicados en los procesos de intervención. Actitudes positivas respecto a la participación y al trabajo en equipo, así como actitudes abiertas a la reflexión, a análisis de la realidad y a la investigación son especificaciones de una actitud permanente de cambio que debe acompañar al conjunto de personas que conviven en una misma realidad y, especialmente, a los directivos que quedan implicados en ella.

Las estrategias que podemos utilizar desde una perspectiva cultural y bajo un enfoque cooperativo suponen un conjunto de decisiones y acciones fundamentadas relativas a la elección de medios y a la articulación de recursos con miras a lograr un objetivo.

El cuadro 7 recoge a modo de ejemplo un conjunto de estrategias que serían coherentes con el planteamiento que presentamos. Cabe señalar, asimismo, que la delimitación de estrategias en contextos colaborativos se vincula a los procesos de planifi- 
cación, es contextualizada, se relaciona con procesos reflexivos y de resolución de problemas y tiene una alta vinculación con el sistema de relaciones humanas de la organización.

Salvando las acciones que el sistema educativo pueda impulsar desde una perspectiva externa (normativas de obligado cumplimiento, facilitación de recursos humanos, materiales o funcionales, presión social -demográfica, cultural-,...), el cuadro 7 refiere las estrategias globales y las operativas, desarrolladas ampliamente en Gairín, (1996a).

Las estrategias de carácter global se identifican como tales por incidir en toda la organización y afectar a todos sus componentes. Suponen o conllevan una modificación de los objetivos institucionales, un cambio en las estructuras y una alteración de los procesos organizativos, al mismo tiempo que una modificación de las dinámicas relacionales. Subyace a todas ellas la idea del centro educativo como un lugar de cambio y de formación, como una institución que aprende y que genera cambios en su cultura.

Llamamos estrategias operativas a aquellas formulaciones que poniendo énfasis en la secuencia de acción proporcionan herramientas para la intervención en grupos humanos y organizaciones. De hecho, se podrían caracterizar en muchos casos como procedimientos y en otros como técnicas. No obstante, mantenemos la idea de estrategia para indicar el carácter abierto que debe tener su aplicación.

Las estrategias que a modo de ejemplo se mencionan en el cuadro 7 no pretenden agotar todas las posibilidades y tan sólo ejemplificar algunas situaciones con vistas a revisar el valor de su utilidad. Cabe también considerar la posibilidad de mezclar varias de las estrategias presentadas y de apoyarlas en técnicas de dinámica de grupo, de resolución de conflictos y de generación de consensos.

\begin{tabular}{|l|c|c|}
\hline \multicolumn{1}{|c|}{$\begin{array}{c}\text { ESTRATEGIAS DE } \\
\text { CARÁCTER GLOBAL }\end{array}$} & ESTRATEGIAS DE CARÁCTER OPERATIVO \\
\hline - El Desarrollo Organizacional (D.O.). \\
- La Revisión Basada en la Escueta (R.B.E.) \\
- La Revisión Departamental. \\
- El Desarrollo Colaborativo.
\end{tabular}

Cuadro 7: Estrategias de intervención con grupos de profesores (Gairín, 1996a:X) 
La utilización de estrategias en la organización y funcionamiento de los centros educativos debe mantener, sin embargo, un sentido instrumental respecto a los objetivos institucionales. Sin embargo, su incidencia en la ordenación de la realidad es tan alto que a menudo se convierten en fines. Ocurre ello cuando los objetivos son difusos o se piensan lo instrumental como única vía factible en la resolución de problemas.

Se olvida en este contexto que las organizaciones son meras ficciones sociales que se materializan a través de sus componentes pero no por sus componentes, que cambian con el tiempo y ayudan a configurar una identidad que les supera.

Por ello, parece lógico asumir en el análisis realizado la existencia de componentes ideológicos y prácticos en la base de cualquier elección que sobre estrategias se realice, sin que ello haya de mermar el carácter relativo que se da a la elección efectuada. Adquiere, así, tanta importancia la estrategia elegida como el que la ha de aplicar.

La intervención de los directivos no sólo parece fundamental por lo que representan en la organización sino por la capacidad que se les supone que tienen para estructurar adecuados contextos de relación a partir de la selección y aplicación que realizan de determinadas estrategias.

\section{Algunas consideraciones finales}

El análisis realizado hasta el momento presupone la existencia de una cierta coherencia entre el nivel organizativo alcanzado y las formas de entender la educación y su práctica. Asimismo, desarrolla dos referencias fundamentales para las organizaciones que se sitúan en el segundo estadio.

La misma complejidad institucional permite identificar, no obstante, contradicciones constantes. Así, es posible que un centro que se sitúa organizativamente en el estadio 1 aplique modelos culturales de formación permanente y defienda estructuras cooperativas de coordinación. Igualmente, se puede pensar en potenciar procesos organizativos propios de un contexto formativo sin modificar los modelos de educación/enseñanza o la forma de realizar la formación permanente.

\begin{tabular}{|c|c|c|c|c|c|c|}
\hline $\begin{array}{c}\text { Nivel } \\
\text { Organizativo }\end{array}$ & $\begin{array}{c}\text { Modelo } \\
\text { Educativo }\end{array}$ & $\begin{array}{l}\text { Modelo de } \\
\text { Enseñanza }\end{array}$ & $\begin{array}{c}\text { Perfil } \\
\text { Profesional }\end{array}$ & $\begin{array}{c}\text { Modelo de } \\
\text { F. Permanente }\end{array}$ & $\begin{array}{c}\text { Desarrollo de } \\
\text { Estructuras }\end{array}$ & $\begin{array}{l}\text { Estrategias } \\
\text { Utilizadas }\end{array}$ \\
\hline \multirow[t]{2}{*}{$\mathrm{O}$} & $\theta$ & $\theta$ & $a$ & & & \\
\hline & 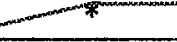 & w & & & & \\
\hline * & $-B$ & & - & ه & $\begin{array}{l}0 \\
0\end{array}$ & $m *$ \\
\hline G & & $-p$ & & & & $n$ \\
\hline
\end{tabular}

Gráfico 7: Algunas contradicciones de la realidad

Estas contradicciones pueden ser asumibles de entrada, si existe el compromiso de disminuir las disfunciones y de hacer más coherente el funcionamiento del cen- 
tro. Este sería, desde mi punto de vista, un referente claro en el compromiso con la calidad.

No hemos de olvidar, tampoco, que los estadios organizativos se incluyen entre sí. La organización no sería un buen contexto si no es un buen marco; no aprende si no es un buen contexto, organizado y con capacidad de luchar por una determinada idea. Paralelamente, hemos de pensar que si no es un buen marco, no es un buen contexto $y$, por tanto, no tiene capacidad de aprendizaje.

De hecho, podriamos hablar más de un "buble" que de estadios organizativos. Formarían parte de la espiral de la mejora la ordenación estructural de la organización, su enriquecimiento como contexto, su intervención sobre él (organización como texto) y el establecimiento de mecanismos que permitieran el aprendizaje organizacional (organización que aprende).

Aunque es difícil conocer con exactitud como son (o deben ser) las organizaciones que aprenden, si que podemos hablar de los principios de aprendizaje que subyacen en este tipo de organizaciones. Tales principios hablan de un aprendizaje orientado a la resolución de problemas, de aprendizaje cíclico (hacer, reflexionar, pensar, decidir, hacer,..) y de aprendizaje por medio de la acción y que se desenvuelve en un contexto ("organización que aprende") caracterizado por Swieringa y Wierdsma (1995:79) como:

$\begin{array}{ll}\text { Estrategia } & \text { Desarrollo continuo } \\ & \text { - dirigido a la misión } \\ & \text { - corto y mediano plazo } \\ & \text { racional e intuitivo } \\ \text { - diversos enfoques }\end{array}$

Estructura Redes orgánicas

- Unidades y equipos combinados flexiblemente

- con base en combinaciones de mercado y producto

- descentralización

- mezcla de pensadores (staff) y hacedores (línea)

- coordinación a través de la discusión

Cultura

Cultura orientada a las tareas

- flexible

- orientada a la resolución de problemas

- creativa

Sistemas

\section{Sistemas de apoyo}

- información para reflexionar, "sobre el sistema"

- información para actuar, "dentro del sistema"

- lidiar con lo complejo

No podemos olvidar en este contexto el ya mencionado cambio de rol y sentido de la dirección. El análisis efectuado (Cuadro 8) permite hablar de un modelo que 
evoluciona hacia una dirección comprometida con el cambio y vinculada a las demandas de los usuarios y a las exigencias del entorno.

\begin{tabular}{|c|c|c|}
\hline $\begin{array}{l}\text { SITUACIONES } \\
\text { DE REFERENCIA }\end{array}$ & $\begin{array}{l}\text { ORIENTACIÓN DE } \\
\text { LA ORGANIZACIÓN }\end{array}$ & $\begin{array}{l}\text { ACTUACIONES } \\
\text { DE LA DIRECCIÓN }\end{array}$ \\
\hline $\begin{array}{l}\text { LAORGANIZACIÓN } \\
\text { COMO MARCO }\end{array}$ & $\begin{array}{l}\text { - Objetivos explícitos y estables. } \\
\text { - La estructura suele ser rígida } \\
\text { - El desarrollo personal es informal o } \\
\text { se considera una opción personal }\end{array}$ & $\begin{array}{l}\text { - La dirección suele ser autocrática. } \\
\text { - La asignación de puestos se basa en } \\
\text { - cualidades personales. } \\
\text { Preocupación por el organigrama. }\end{array}$ \\
\hline $\begin{array}{l}\text { LA ORGANIZACIÓN } \\
\text { COMO CONTEXTO }\end{array}$ & $\begin{array}{l}\text { - Objetivos cambiantes según las } \\
\text { exigencias del contexto. } \\
\text { - La estructura es adaptativa y se } \\
\text { orienta al usuario. } \\
\text { - La formación se considera como } \\
\text { un soporte puntual }\end{array}$ & $\begin{array}{l}\text { - La dirección permite la participación } \\
\text { - Se enfatiza en los procesos de } \\
\text { coordinación y especialización. } \\
\text { - Preocupación por las demandas de } \\
\text { los usuarios. }\end{array}$ \\
\hline $\begin{array}{l}\text { LA ORGANIZACIÓN } \\
\text { APRENDE }\end{array}$ & $\begin{array}{l}\text { - Existen ideas básicas compartidas. } \\
\text { - Hay autonomía de gestión. } \\
\text { - La formación forma parte de la } \\
\text { estrategia organizacional y de las } \\
\text { funciones laborales. }\end{array}$ & $\begin{array}{l}\text { - La dirección promueve la } \\
\text { colaboración. } \\
\text { - Se crean equipos de trabajo. } \\
\text { - Atención a las demandas de los } \\
\text { usuarios y al desarrollo continuo } \\
\text { del personal. }\end{array}$ \\
\hline
\end{tabular}

Cuadro 8: La actuación de la dirección en función de los niveles organizativos (Gairín, 1997c:70)

Por otra parte, y en la referencia a contextos más amplios que el aquí tratado, hemos de referenciar, aunque sea a nivel testimonial, el alineamiento de la escuela que aprende con aportaciones parciales que hablan de la "escuela total" (Tedesco, 1995), la educación como "utopía necesaria" (UNESCO, 1996), la necesaria reestructuración de las escuelas (Elmore y otros, 1996), de los problemas de las escuelas (Mclaren, 1984; Calvo, 1996), las escuelas democráticas (Apple y Beare) o de las nuevas visiones de las organizaciones como revoluciones perpetuas (Peters, 1995), entre otras cuestiones.

\section{Bibliografía}

AGUERRONDO, I. (1993): Como será la escuela del siglo XXI. En FILMUS, D. (Coord): Para que sirve la escuela. Tesis, Buenos Aires, págs 147-164.

ANTÚNEZ, S. (1994): La autonomía de los centros escolares, factor de calidad educativa y requisito para la innovación. En Revista de Educación, n² 304, mayo.Agosto, págs 81-112.

APPLE, M.W. y BEARE, J.A. (Comp): (1997): Escuelas democráticas. Morata, Madrid.

BLANCHARD, K. Y O' CONNOR, M. (1997): Dirección por valores. Gestión 2.000, Madrid.

CALVO DE MORA, J. (1996): Claves para la organización de la práctica escolar. Método, Granada.

ELMORE, R.F. y OTROS (1996): La reestructuración de las escuelas. Fondo de Cultura Económica, México. 
GAIRÍN, J. (1986): La prefectura d'estudis. Els Departaments i els Equips Educatius. Curs de Directors de centres públics. U.D. 3.3.1. Departament d'Ensenyament, Generalit de Catalunya.

GAIRÍN, J. (1992): La dinamización del centro escolar. Estrategias para la mejora de la calidad educativa. En Actas del primer congreso internacional sobre dirección de centros educativos. ICE, Universidad de Deusto, Bilbao.

GAIRÍN, J. (1993): La innovación en organizaciones educativas. En Primer Congreso Internacional de Administración Educacional. Universidad de La Serena (Chile), Octubre (documento policopiado).

GAIRín, J. (1996): La organización escolar. Contexto y texto de actuación. La Muralla, Madrid.

GAIRÍN, J. (1997a): El contexto interno. En GAIRÍN, J y FERRÁNDEZ, A. (Coord): Planificación y gestión de instituciones de formación. Praxis, Barcelona, págs 81 127.

GAIRÍN, J. (1997b): La organización escolar. Contexto para un proyecto de calidad educativa. En Actas del Cuarto Congreso de Educación y Gestión: calidad educativa para una Europa de calidad. Valladolid, págs 105-166.

GAIRÍN, J. (1997c): La dirección en los procesos de aprendizaje colectivo. En Alta Dirección, no 191 , págs. 69-77

GOMEZ LLERA, G. y PIN, J.R. (1994): Dirigir es educar. McGraw Hill, Madrid.

GONZÁLEZ, Ma T. (1991): La función del liderazgo instructivo como apoyo al desarrollo de la escuela. En GID (Coord.): Cultura escolar y desarrollo organizativo. Universidad de Sevilla, págs 37-46.

HABERMAS, T. (1982): Conocimiento e interés. Taurus, Madrid.

LÓPEZ, F. (1994): La gestión de calidad en educación. La Muralla, Madrid

MCLAREN, P. (1984): La vida en las escuelas. Siglo XXI, Madrid.

PETERS, T. (1995): Nuevas organizaciones en tiempos de caos. Deusto, Bilbao.

RICCARDI, R. (1965): Organización y formación. Bilbao. Deusto.

SAN FABIAN, J.L. (1992): Gobierno y participación en los centros escolares: sus aspectos culturales. En GID (Coord.): Cultura escolar y desarrollo organizativo. Universidad de Sevilla.

SANTOS, M.A. (1995): Organizaciones que educan. En Gairín, J. y Darder, P.: Organización y gestión de centros educativos. Praxis, Barcelona, págs 470/17 a $470 / 23$.

SENGE, P. (1992): La quinta disciplina. El arte y práctica de la organización abierta al aprendizaje. Granica, Barcelona.

SHOWERS, B. (1985): Beyond the stable state. Temps Smith, Londres.

STAHL, TH. y OTROS (1993): La organización cualificante. Comisión de las Comunidades Europeas, EUROTECNET.

SWIERINGA, J.y WIERDSMA, A. (1995): La organización que aprende. Addison Weslers, Iberoamérica, Buenos Aires.

TEDESCO, J.C. (1995): El nuevo pacto educativo. Anaya, Madrid.

UNESCO (1996): La educación encierra un tesoro. Informe de la UNESCO de la Comisión Internacional sobre la educación para el siglo XXI, presidida por Jacques Delors. Santillana- Ediciones UNESCO, Madrid. 